\title{
Value of routine electrocardiography in hypertensive patients
}

\author{
C. F. George, A. M. Breckenridge, and C. T. Dollery \\ From the Medical Research Council Clinical Pharmacology Research Group, \\ Royal Postgraduate Medical School, Ducane Road, London W.I2
}

Serial electrocardiograms have been compared in a group of 50 surviving patients who have received hypotensive therapy for at least five years and in 20 similar patients who died of myocardial infarction. The incidence of voltage changes suggesting left ventricular hypertrophy was higher in the infarct group, but in both cases there was a significant correlation between the summed voltage of the $S$ wave in $V_{I}$ and the maximum $R$ wave voltage in $V_{5}$ or V6 and the level of systolic pressure at presentation. After the introduction of hypotensive therapy, $37(74 \%)$ of the surviving group showed a reduction in praecordial voltage and only 7 (14\%) had increased voltage. In the infarct patients, $10(50 \%)$ developed increased voltage before the infarction. This difference is highly significant $(P<0.01)$ but probably reflects suboptimal pressure regulation in the infarct group. There was a highly significant correlation between praecordial voltage and the average systolic pressure control over the period of treatment $(P<0.001)$. Abnormalities of repolarization were present in 60 per cent of the initial electrocardiograms in both groups. The depth of $S T$ segment depression in the initial electrocardiogram was related to the level of systolic pressure but no relation could be identified for the height of the $T$ wave or the depth of its inversion and blood pressure.

No electrocardiographic features predictive of future myocardial infarction were identified but it is suggested that the sum of $S V I$ and $R V 5 / V 6$ is a useful index of systolic pressure control. Increasing praecordial voltage is found in patients with suboptimal pressure regulation and these patients are particularly likely to suffer vascular complications of hypertension.

Since the introduction of modern hypotensive therapy there has been a conspicuous improvement in the prognosis of hypertensive patients (Harington, Kincaid-Smith, and McMichael, 1959; Smirk and Hodge, I963; Breckenridge, Dollery, and Parry, 1970). The mortality from renal failure and cerebrovascular accidents in particular has been reduced (Hamilton, Thompson, and Wisniewski, I964; Breckenridge et al., 1970). In spite of these encouraging trends in overall prognosis the proportion of deaths from myocardial infarction has increased (Smirk and Hodge, 1963; Breckenridge et al., 1970). Since it has been claimed that electrocardiographic changes can identify patients at risk from coronary artery disease (Sokolow and Perloff, 196I; Truett, Cornfield, and Kannel, 1967), we have examined their predictive value in a group of treated hypertensive patients. All patients attending the hypertension clinic

Received 9 August 197 I. have an electrocardiogram recorded before treatment is begun and this investigation is repeated annually or more frequently as indicated. Thus, we have been able to conduct a retrospective study of electrocardiographic changes occurring in a group of hypertensive patients and compare the findings with those obtained in a group of patients from our clinic who died of myocardial infarction.

\section{Subjects and methods}

Fifty patients who have attended the hypertension clinic for at least five years formed the first group (Group I). These patients were selected by drawing seven case records at six successive clinics and eight records on the seventh week. This was done without earlier knowledge of blood pressure control or electrocardiographic findings. The following information was extracted.

I) Pretreatment blood pressure values and levels recorded at all outpatient attendances since starting treatment Systolic and diastolic pressure control during the period of follow- 
up was calculated for each patient by taking the average of all values recorded both lying and standing.

2) Changes in the electrocardiogram An analysis of the electrocardiogram was made for changes in left ventricular hypertrophy by voltage criteria (Sokolow and Lyon, 1949) and measurements of the height of the $R$ and $T$ waves in leads $V_{5}$ and V6 were recorded. In addition, the depth of the $S$ wave in VI and of ST segment depression in V5 and V6 were measured. These analyses were performed on both the pretreatment electrocardiogram and on the most recent record.

3) Age, sex, weight, smoking habits, details of chest pain, retinal grading, and levels of blood urea and serum cholesterol These were entered with the previous information on punch cards.

The case notes of the last 20 treated hypertensive patients who had died of myocardial infarction five or more years after their first attendance at Hammersmith Hospital were examined in the same manner (infarct group). Recumbent pressures were not recorded in 6 of these patients so that the pressures taken seated and standing were used for estimating their average systolic and average diastolic pressures.

Numerical data from the two groups were analysed by an unpaired Student's t-test. A $\chi^{2}$ analysis was used for comparing other differences between the two groups. Correlations between electrocardiographic findings and blood pressure data were obtained from regressions computed by the least squares method.

\section{Results}

The results obtained are summarized in Table I and Table 2. There was a close similarity in age, smoking habits, and blood pressure at presentation in the two groups. The proportion of males was higher in the infarct group, 15/20 (75\%) compared with 26/50 $(52 \%)$, but this was not statistically significant $(\mathbf{P}>0 \cdot I)$. Serum cholesterol figures were available in $4 I$ patients in group $I$ and IS patients in the infarct group and were not significantly different. Levels of blood urea were similar in the two groups, but the severity of hypertension as judged by the retinal findings was greater in the infarct group $\left(\chi^{2}=4 \cdot 134 ; P<0.05\right)$.

Initial electrocardiographic findings I) Praecordial voltage In group I, 20 patients $(40 \%)$ had summed $S$ VI and R maximum V5/V6 voltages of $35 \mathrm{~mm}$ or greater. An additional 5 patients had $R$ waves in AV1 greater than Io $\mathrm{mm}$. Therefore, 25 (50\%) of group I patients had voltage changes suggesting left ventricular hypertrophy. In the infarct group there was a higher incidence of
TABLE I

\begin{tabular}{llll}
\hline & Group I & Infarct group & Significance \\
\hline Total No. & 50 & 20 & \\
Average age (yr) & $59 \cdot 3 \pm 8 \cdot 7$ & $60 \cdot 0 \pm 7 \cdot 8$ & $\mathrm{NS}$ \\
Male:Female & $26: 24$ & $15: 5$ & $\mathrm{NS}$ \\
Pressure at initial visit (mmHg) & & & \\
$\quad$ Systolic & $220 \cdot 3 \pm 28 \cdot 7$ & $228 \cdot 0 \pm 31 \cdot \mathrm{I}$ & $\mathrm{NS}$ \\
$\quad$ Diastolic & $129 \cdot 1 \pm 14 \cdot 9$ & $131 \cdot 1 \pm 16 \cdot 9$ & $\mathrm{NS}$ \\
Smoking habits (cigs/day) & 7 & 10 & $\mathrm{NS}$ \\
Retinal grade 3 or 4 & $17(34 \%)$ & $12(60 \%)$ & $<0 \cdot 05$ \\
Blood urea (mg/roo ml) & $36 \cdot 8 \pm 12 \cdot 6$ & $43 \cdot 7 \pm 19 \cdot 4$ & $\mathrm{NS}$ \\
Serum cholesterol (mg/roo ml) & $267 \cdot 0 \pm 65 \cdot \mathrm{I}$ & $276 \cdot 7 \pm 61 \cdot 3$ & $\mathrm{NS}$ \\
& $(4 \mathrm{I})$ & $(15)$ & \\
\hline
\end{tabular}

voltage changes, I6 patients $(80 \%)$ fulfilling the previous criteria but this difference was not significant.

There was a significant correlation between the level of pretreatment systolic pressure and the summed voltage of the $S$ wave in $\mathrm{VI}$ and the maximum $R$ in V5/V6 both for group I $(\mathbf{P}<0.05)$ and the infarct group $(\mathbf{P}<0.05)$. Since an analysis of variance showed that the calculated regression lines did not differ significantly, the data for the two groups were pooled (Fig. I) giving a $P$ value $<0.00 I$.

No correlation was shown in either group between the diastolic pressure and the summed S VI and R V5/V6 voltage.

2) ST segment and $T$ wave abnormalities Abnormalities of repolarization were found in 30 of 50 patients in group I $(60 \%)$. Only 8 of these patients gave a history of chest pain. There was a similar incidence in the infarct group, I2 $(60 \%)$ of the initial electrocardiograms showing these changes.

There was a significant correlation between the level of systolic pressure at presentation and the degree of ST segment depression in V5/V6 $(P<0.0 I)$ in group I patients. No correlation was found between the height of the $T$ wave or the depth of its inversion and the level of systolic pressure at presentation. In the infarct group no correlation was found between the initial systolic pressure and either ST segment depression or the height of the $\mathrm{T}$ wave in $\mathrm{V}_{5} / \mathrm{V} 6$.

TABLE 2

\begin{tabular}{lcll}
\hline & Group I & Infarct group & Significance \\
\hline Left ventricular hypertrophy on & & & \\
electrocardiogram at presentation & $25(50 \%)$ & $16(80 \%)$ & NS \\
Voltage increase with time & $7(14 \%)$ & $10(50 \%)$ & $\mathbf{P}<0.01$ \\
'Average' pressure control & $163.6 \pm 19.7$ & $186.5 \pm 22.1$ & $\mathrm{P}<0.00 \mathrm{I}$ \\
Systolic & $98.1 \pm 7.9$ & $109.1 \pm 9.7$ & $\mathrm{P}<0.001$ \\
Diastolic & & & \\
\hline
\end{tabular}




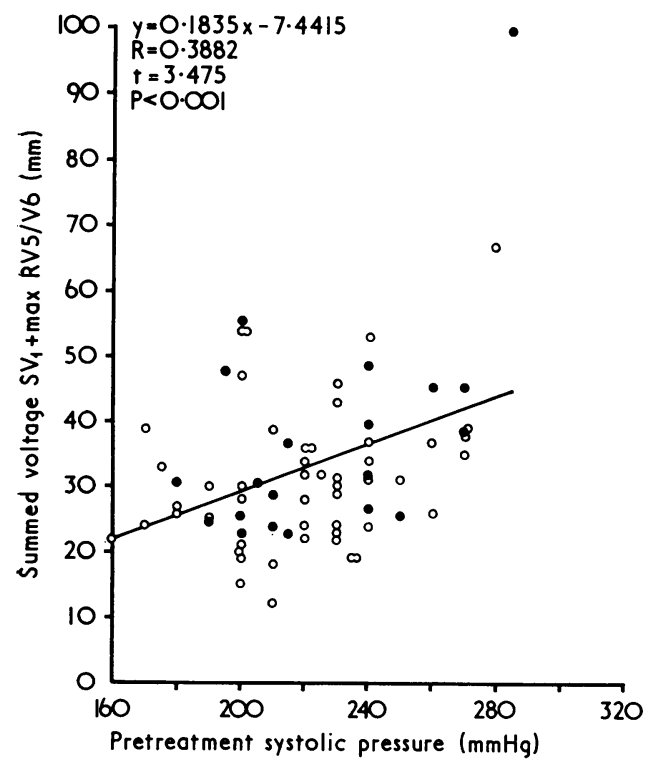

FIG. I Regression of summed $S V I+$ maximum $R V_{5} / V 6$ voltage (in $\mathrm{mm}$ ) on pretreatment systolic blood pressure. Group $I=0$, infarct patients $=\mathbf{\bullet}$.

There was no relation between the initial diastolic pressure and repolarization changes in either the infarct group or group I $(P>0 \cdot 10)$. No correlation was found between the height of the R wave in V5 or V6 and the height of the $T$ wave in these leads.

Changes in electrocardiographs after treatment of hypertension After treatment of hypertension there was a reduction in voltage in the praecordial leads in 74 per cent of patients in group $\mathrm{r}$. Since there was a considerable variation in the initial summed praecordial voltage, the reduction which occurred has been expressed as percentage alteration in voltage. This measurement showed a significant correlation with the extent of systolic pressure reduction $(\mathbf{P}<0.05)$. (Six patients who developed a bundle-branch block or who had voltage loss due to unequivocal myocardial infarction in the most recent electrocardiogram were excluded from the analysis.)

Seven patients (14\%) in group I showed an increase in voltage between the pretreatment and latest electrocardiogram. In contrast, Io patients (50\%) in the infarct group showed an increase in voltage on the last electrocardiogram recorded before myocardial infarction. This difference is highly significant $(\mathrm{P}<0.01)$. A further difference between the two groups was that blood pressure control was significantly worse in the infarct group average, where it was $186.5 / 109.1$ than in group I, where it was 163.6/98.I $(P<0.001$ for both systolic and diastolic values). In view of the correlation found between initial praecordial voltage and the systolic pressure at first visit, it seemed possible that increasing voltage on the electrocardiogram was related to poor systolic pressure control. We therefore compared the summed voltage of $S \mathrm{VI}$ and $\mathrm{R} \mathrm{V5/V6} \mathrm{in} \mathrm{the} \mathrm{most} \mathrm{recent} \mathrm{electrocardio-}$ gram with the average systolic pressure achieved and for both groups we have shown a highly significant correlation $(P<0.001)$ (Fig. 2).

In order to test this hypothesis further, a limited study was done on the last I 5 patients who died of a cerebrovascular accident five or more years after starting hypotensive therapy. Systolic pressure was poorly controlled relative to patients in group $\mathrm{I}$, mean $=193 \pm 27.6$ $\mathrm{mmHg}$ and the praecordial voltage increased in 5 patients. These findings do not differ significantly from those in the infarct group. An analysis in all three groups by the MantelHaenszel formula for combination of relative risk (Snedecor and Cochran, 1967) showed that the risk of developing increasing praecordial voltage when the average systolic

FIG. 2 Regression of summed $S V I+$ maximum $R$ V5/V6 voltage (in $\mathrm{mm}$ ) on average systolic pressure during treatment. Group $I=0$, infarct patients $=0$.

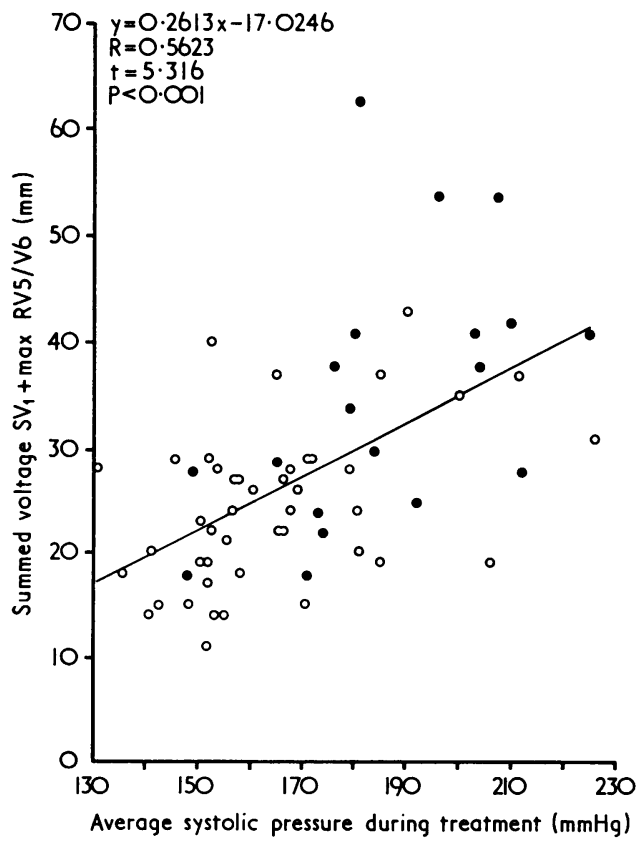


pressure was greater than $180 \mathrm{mmHg}$ was 5.43 times the risk where the average systolic pressure was under $180 \mathrm{mmHg}$.

In group $\mathrm{I}$ increase in $\mathrm{T}$ wave voltage and a reversal of previously inverted $T$ waves was common after treatment but could not be correlated with the degree of pressure control. The improvement in amplitude of the $T$ wave reflected the degree of initial abnormality, highly abnormal waves showing the greatest change $(\mathbf{P}<0.00 \mathrm{r})$. There was, however, a correlation between the level of systolic pressure $(P<0.05)$ but not diastolic pressure and the depth of ST segment depression in the most recent electrocardiogram.

In the infarct group there was also a correlation between the level of systolic pressure and the depth of ST segment depression after treatment $(P<0.05)$. $T$ wave inversion became more pronounced in several patients but was not related to either systolic or diastolic pressure regulation.

\section{Discussion}

The major electrocardiographic abnormalities which arise as a result of hypertension are high voltage, left axis deviation, and changes in the ST segment and $T$ waves. Several workers have defined voltage criteria for left ventricular hypertrophy, including Sokolow and Lyon (1949). Though these criteria lack specificity (Allenstein and Mori, 1960) and may be affected by age, race, posture, and thickness of the chest wall, they are simple to derive and highly sensitive. Despite these limitations, we have shown a striking correlation between praecordial voltage and systolic pressure at the initial examination and, more significantly, after five years of hypotensive therapy.

Without treatment, the majority of hypertensive patients develop increasing voltage on the electrocardiogram (Master, 1930; Cosby, Herman, and Mayo, 1962) and repolarization changes. Canabal, Warneford-Thomson, and White (1945) found that over the course of five years 50 per cent deteriorated, 40 per cent remained unchanged, and ro per cent showed questionable improvement. In contrast, after lumbodorsal sympathectomy White et al. (1945) found that only 12.7 per cent showed a deterioration, 29.8 per cent remained unchanged, and 57.5 per cent of the cardiograms improved. Subsequently, Doyle (1953) found a reduction in QRS amplitude in 49 of 75 $(65 \%)$ patients treated with methonium compounds for one year. In our series of 50 patients who currently attend the clinic, only 7 (14\%) showed an increase in praecordial voltage over five years and $37(74 \%)$ showed a decrease in voltage. In contrast, in those who developed myocardial infarction there was a higher incidence of voltage changes at presentation, and after treatment 50 per cent had increased QRS amplitude. Systolic pressure control was significantly worse in the infarct group, and there was a good correlation between it and praecordial voltage. In view of this and the high ratio of relative risk shown by the Mantel-Haenszel analysis, poor pressure control was the probable cause of the increasing QRS amplitude. It is also possible that poor pressure control was a major factor in the occurrence of fatal myocardial infarction and cerebrovascular accidents.

ST segment and $\mathrm{T}$ wave abnormalities are common in the electrocardiograms of hypertensive patients (Barnes and Whitten, I929; Evans, Mathews, and White, 1945), but their significance has been debated since Linetzky's (I9I I) statement that there was a correlation between them and the level of systolic pressure. A recent study by Hamer, Shinebourne, and Fleming (1969) in 17 patients supports this belief. Our observations to some extent confirm Linetzky's findings in that we have shown a correlation between the height of systolic pressure and the depth of ST depression in group I patients both before and after treatment and in the infarct group after treatment. However, we failed to show any relation between measurements of the $T$ wave and the level of pressure. An alternative explanation considered by Leishman (I95I) is that repolarization changes reflect myocardial ischaemia. Such abnormalities are more common over the age of 50 (Simpson, 1960) and carry a poor prognosis (Sokolow and Perloff, I96I; Blackburn, Taylor, and Keys, 1970). However, in our patients the incidence of repolarization changes was almost identical in those with and without a history of ischaemic cardiac pain in group I and those in the infarct group. It therefore appears that hypertension was a more important cause of repolarization changes in these patients than myocardial ischaemia.

Since major electrocardiographic abnormalities are common in hypertensive patients, it has not proved possible to predict a future myocardial infarction on this basis. However, assessment of summed $S$ VI and $R$ maximum $\mathrm{V}_{5} / \mathrm{V} 6$ is a useful index of systolic pressure control, an increase in this measurement after several years of hypotensive therapy suggesting suboptimal pressure regulation.

We wish to thank the Departments of Biochemistry and Cardiology for their help in this study. 


\section{References}

Allenstein, B. J., and Mori, H. (1960). Evaluation of electrocardiographic diagnosis of ventricular hypertrophy based on autopsy comparison. Circulation, 21, 401 .

Barnes, A. R., and Whitten, M. B. (1929). Study of $T$-wave negativity in predominant ventricular strain. American Heart fournal, 5, I4.

Blackburn, H., Taylor, H. L., and Keys, A. (1970). The electrocardiogram in prediction of five-year coronary heart disease incidence among men aged forty through fifty-nine. Circulation, 41, Suppl. 4, I54.

Breckenridge, A., Dollery, C. T., and Parry, E. H. O. (1970). Prognosis of treated hypertension: changes in life expectancy and causes of death between I952 and 1967. Quarterly fournal of Medicine, 39, 4 II.

Canabal, E. J., Warneford-Thomson, H. F., and White, P. D. (1945). The electrocardiogram in hypertension. III. Electrocardiograms of hypertensive patients followed for a long time without splanchnic resection in comparison with those in patients who had had splanchnic resection. American Heart fournal, 30, 189.

Cosby, R. S., Herman, L. M., and Mayo, M. (1962). Sequential changes in the development of the electrocardiographic pattern of left ventricular hypertrophy in hypertensive heart disease. American Heart fournal, 63, 180.

Doyle, A. E. (1953). Electrocardiographic changes in hypertension treated by methonium compounds. American Heart fournal, 45, 363.

Evans, E., Mathews, M., and White, P. D. (1945). The electrocardiogram in hypertension: I. Its description. American Heart fournal, 30, I40.

Hamer, J., Shinebourne, E., and Fleming, J. (1969). Significance of electrocardiographic changes in hypertension. British Medical fournal, $\mathbf{1}, 79$.

Hamilton, M., Thompson, E. N., and Wisniewski, T. K. M. (r964). The role of blood-pressure control in preventing complications of hypertension. Lancet, 1, 235.
Harington, M., Kincaid-Smith, P., and McMichael, J. (1959). Results of treatment in malignant hypertension, a seven-year experience in 94 cases. British Medical fournal, 2, 969.

Leishman, A. W. D. (I95I). The electrocardiogram in hypertension. Quarterly fournal of Medicine, 20, $I$.

Linetzky, S. (I9II). Die Beziehungen der Form des Elektrokardiogramms zu dem Lebensalter, der Hegrosse und dem Blutdruck. Zeitschrift für experimentelle Pathologie und Therapie, 9, 669.

Master, A. M. (1930). Characteristic electrocardiograms and roentgenograms in arterial hypertension. American Heart fournal, 5, 291.

Simpson, F. O. (1960). Electrocardiographic signs of left ventricular hypertrophy and strain in hypertensive patients. British Heart fournal, 22, 227.

Smirk, F. H., and Hodge, J. V. (I963). Causes of death in treated hypertensive patients. British Medical fournal, 2, 1221 .

Snedecor, G. W., and Cochran, W. G. (1967). Statistical Methods, 6th ed. Iowa State University Press, Ames, Iowa.

Sokolow, M., and Lyon, T. P. (1949). The ventricular complex in left ventricular hypertrophy as obtained by unipolar precordial and limb leads. American Heart fournal, 37, 16r.

Sokolow, M., and Perloff, D. (I96I). The prognosis of essential hypertension treated conservatively. Circulation, 23, 697.

Truett, J., Cornfield, J., and Kannel, W. (1967). A multivariate analysis of the risk of coronary heart disease in Framingham. Fournal of Chronic Diseases, 20, 5 II.

White, P. D., Smithwick, R. H., Mathews, M. W. and Evans, E. (1945). The electrocardiogram in hypertension: II. The effect of radical lumbodorsal sympathectomy. American Heart fournal, 30, 165.

Requests for reprints to Dr. C. F. George, Royal Postgraduate Medical School, Hammersmith Hospital, Ducane Road, London W.r2. 